Artículo DE Revisión

\section{Reacción de la pulpa dentaria ante la presencia de la caries y los tratamientos dentales}

Dental pulp reaction before the presence of decays and dental treatments

\section{Resumen}

Este artículo revisa las diferentes reacciones de la pulpa dentaria ante las injurias provocadas por la caries dental y por los diferentes tratamientos restauradores que se realizan sobre ella, de donde se deduce como objetivo principal el dar a conocer al odontólogo de práctica general, los conocimientos pertinentes para orientar, prevenir y conservar la salud de la pulpa dentaria.

Palabras Clave: Caries dental, tratamientos restauradores, pulpa dentaria.

\begin{abstract}
This article reviews the different reactions of the dental pulp before the injuries caused by dental caries and by the different restoration treatments performed on it. Therefore, it was concluded that the main objective is to provide the general practice dentist with the pertinent knowledge to orient, prevent and maintain the dental pulp health.
\end{abstract}

Key words: Dental decays, restoration treatments, dental pulp.

\section{Víctor Velásquez Reyes ${ }^{1}$ María Álvarez Páucar ${ }^{2}$}

\author{
${ }^{1}$ Profesor Asociado del D.A. de Estomatología \\ Pediátrica \\ Profesor Auxiliar del D.A. de Estomatología \\ Pediatrica \\ Facultad de Odontología, Universidad Nacional \\ Mayor de San Marcos
}

Correspondencia:

Mg. C.D. Velásquez Reyes Víctor Manuel

Facultad de Odontología, UNMSM. Av. Germán Amézaga s/n, Lima 1. Perú

e-mail: v.velasquez.r@gmail.com

\section{Introducción}

Se sabe que la dentina avanza su crecimiento hacia dentro a partir de la cubierta epitelial, (que incluye una zona de tejido que constituye la pulpa dental), esta se ve disminuida al madurar el diente. En ese instante, la velocidad de formación de la dentina es bastante lenta y la pulpa suele persistir toda la vida, pero su volumen va disminuyendo. Entre los componentes de la pulpa sana destacan: una capa exterior, que a su vez constituye la capa interna de la dentina, conformada por los odontoblastos; debajo de esta capa se encuentra la capa acelular, rica en terminaciones nerviosas sensitivas y capilares sanguíneos; la mayor parte de resto pulpar central es parecido al tejido conjuntivo de otras zonas como: células mesenquimatosas, células defensivas, fibroblastos, fibras de colágeno, sustancia fundamental, redes vasculares. Por lo tanto, este tejido da aporte metabólico a los odontoblastos durante la rápida acumulación de tejido dentinario, tanto durante el crecimiento inicial como durante las reparaciones. Si los odontoblastos muriesen, el resto de tejido pulpar (ectomesénquimal) se diferencia en odontoblastoides que elaboran dentina reparadora irregular. Si bien es cierto, la pulpa puede responder a agresiones bajo diferentes formas de inflamación, puede curarse o puede morir. Cabe resaltar que la pulpa se diferencia de los tejidos conjuntivos, por estar rodeada de la dentina y emitir prolongaciones que atraviesan dicha dentina; de ahí que se le considera a la pulpa y a la dentina, como una unidad, llamada complejo dentinopulpar. ${ }^{1}$

Las agresiones (procesos cariosos o restauraciones) son diferentes a las que se observan en otras partes del organismo y ponen en peligro la vida del tejido pulpar. La pulpa puede ser dañada o morir debido a caries dental, microfiltraciones en dientes restaurados y por traumatismos mecánicos, térmicos o químicos. Asimismo, por la exposición pulpar, durante la exéresis del tejido carioso, después de una preparación dentaria por el calor generado al tallar el diente y por los productos químicos aplicados a la dentina, o efectos postoperatorios cuando es aplicada una restauración. ${ }^{1}$

El objetivo del presente trabajo es dar a conocer los efectos de la caries dental y de las restauraciones sobre la pulpa dental.

\section{Material y Método}

Para la realización del presente trabajo, se revisó, analizó y sintetizó el material proveniente de la búsqueda bibliográfi- ca, odontología basada en evidencia de los últimos 15 años, utilizando buscadores Pub Med, Medline y Lilacs, los artículos seleccionados, fueron en idioma inglés, español y portugués, mientras que la búsqueda manual de los textos proceden de los últimos 16 años, en español. Se incluyeron estudios prospectivos, longitudinales y de experimentación entre ellas (tesis, journals, revistas), además de manuales y monografías universitarias, totalizando 18 publicaciones: 15 artículos del período 1990- 2010 y revisión de 03 textos, del período 1991-2008.

\section{Bases teóricas}

\section{El complejo pulpo-dentinario}

La pulpa dental es un tejido conectivo que está situado en un ambiente único ya que se encuentra encerrada en una cámara rígida de dentina mineralizada. La composición y estructura de la pulpa son bastante diferentes de las de la dentina. Sin embargo, los dos tejidos están en relación íntima embriológica y funcionalmente. ${ }^{2}$

El complejo pulpo-dentinario es un concepto importante para entender la patobiología de la dentina y de la pulpa. Durante el desarrollo, las células pulpares producen dentina, nervios y 
vasos sanguíneos, aunque la dentina y la pulpa tienen diferentes estructuras y composiciones, una vez formadas reaccionan frente al estímulo como una unidad funcional. La exposición de la dentina a través de la atrición, el trauma o la caries, produce reacciones pulpares profundas que tienden a reducir la permeabilidad dentinal y a estimular la formación de dentina adicional. Estas reacciones son llevadas a cabo con cambios en los fibroblastos, nervios, vasos sanguíneos, odontoblastos, leucocitos y el sistema inmune. ${ }^{2,3}$ Además, la relación funcional entre la pulpa y la dentina se puede observar cuando la pulpa es capaz de crear dentina fisiológicamente y en respuesta a un estímulo externo, la pulpa contiene nervios que aportan la sensibilidad dentinaria, el tejido conectivo pulpar es capaz de responder a lesiones dentinarias sin ser estimulado directamente y la encapsulación de la pulpa dentro de la dentina crea un ambiente que influencia negativamente su potencial de defensa. ${ }^{2}$

\section{Efectos de la caries sobre la pulpa}

La caries dental es una infección localizada, destructiva y progresiva de la dentina que en su evolución puede ocasionar necrosis pulpar y la potencial pérdida del diente. Los metabolitos bacterianos tales como los ácidos se consideran el inicio de las reacciones pulpares, a pesar de que la capacidad tampón del fluido dentinario probablemente neutralice el $\mathrm{pH}$ antes de que produzca directamente una respuesta perjudicial, excepto en aquellos casos en los que el grosor dentinario remanente sea mínimo. La respuesta inflamatoria a la caries se caracteriza por el acúmulo focal de células inflamatorias crónicas. Este proceso está probablemente mediado, en un estadío inicial, por los odontoblastos y, posteriormente, por las células dendríticas; estas últimas son responsables de la presentación del antígeno y de la estimulación de los linfocitos T. En la pulpa no inflamada, estas células dendríticas se distribuyen de forma diseminada a lo largo de la misma. ${ }^{3}$

En la lesión incipiente, los anticuerpos se acumulan en la capa odontoblástica; con el avance de la lesión, pueden verse en los túbulos dentinarios. Los mediadores neurogénicos están implicados en la respuesta pulpar a los irritantes y, al igual que los componentes del sistema inmune, pueden mediar en el proceso patológico. La estimulación externa de la dentina provoca la liberación de neuropéptidos proinflamatorios desde los nervios aferentes pulpares. Se liberan sustancia $\mathrm{P}(\mathrm{SP})$ y péptido relacionado con el gen de la calcitonina (CGRP, calcitonin gene-related peptide), los cuales producen respuestas vasculares tales como la vaso dilatación y aumento de la permeabilidad vascular, lo que provoca un proceso inflamatorio con edema, calor y dolor.

Esto se traduce en un aumento neto de la presión tisular que puede progresar a necrosis en circunstancias extremas y persistentes. Las investigaciones histofisiológicas demuestran que la vitalidad dentaria depende en mayor grado de su microcirculación que de su mecanismo sensitivo. Se considera que el flujo sanguíneo pulpar es el más rápido del organismo, alcanzando una velocidad de $0,3 \mathrm{~mm} / \mathrm{seg}$ en las arteriolas, de $0,15 \mathrm{~mm}$ en las vénulas, y de $0,08 \mathrm{~mm}$ en los capilares, lo que provoca que la presión sanguínea pulpar sea una de las más elevadas en comparación con otros tejidos orgánicos. El acúmulo de células inflamatorias comienza a ser marcado cuando la lesión cariosa se aproxima a la pulpa y la infección alcanza la dentina terciaria. La exposición pulpar en los dientes deciduos e inmaduros puede provocar una respuesta proliferativa o hiperplásica o formación de un pólipo pulpar por la rica irrigación saguínea, junto con el abundante drenaje linfático y oral. ${ }^{3}$

\section{Efectos de los materiales restaurado- res sobre la pulpa}

Éstos parecen relacionarse directamente con la permeabilidad dentinaria; sin embargo, el grado de permeabilidad es variable y está determinado por diversos factores, incluyendo la edad y estado de la caries, siendo la más importante el grosor de la dentina entre el suelo de la preparación cavitaria y la pulpa (dentina remanente de 0.5 a $2 \mathrm{~mm}$.), lo cual es considerado adecuado para prevenir reacciones pulpares a procedimientos restaurativos.

Los componentes no adhesivos de las resinas y de los agentes de grabado ácido pueden afectar a la pulpa subyacente mediante la inducción de una respuesta inflamatoria. Los estudios han demostrado que ciertos componentes citotóxicos de los monómeros de resina penetran rápidamente en la dentina; sin embargo, el efecto parece ser de corta duración y en ausencia de bacterias, reversible. Algunos componentes de las resinas compuestas se liberan en concentraciones citotóxicas después de que se completa la polimerización, lo que conduce a un estímulo crónico y secundariamente a una respuesta inflamatoria prolongada. ${ }^{4}$

La mayoría de los materiales restauradores se localizan en la proximidad de las pulpas alteradas por una lesión bacteriana y patología previa; la limpieza y la restauración del diente tienen efectos acumulativos sobre la pulpa dental. El potencial irritativo de ciertos materiales restauradores es básico para su utilidad en la restauración dentaria. ${ }^{4}$

\section{Respuesta pulpar a los agentes adhe- sivos dentales}

\section{a. Formación de smear layer o barri- llo dentinal}

Los túbulos dentinales cortados o prismas del esmalte, en un momento dado desaparecen ya que son cubiertos por una capa de desechos o detritos, de menos de 2 um de espesor, constituida principalmente por una mezcla de: componentes de los túbulos dentinales, agua, fluido dentinal y saliva. Esta capa se conoce con el nombre de smear layer o barrillo dentinal. ${ }^{5}$

Si la superficie dentinal preparada posee túbulos abiertos, pequeñas extensiones de estos desechos o detritos pueden extenderse dentro de estos túbulos abiertos y taponarlos. De este modo, se forman los smear plugs, los cuales disminuyen la permeabilidad dentinal hasta en un 86 $\%$. Esta capa de desechos o detritos se disuelve al utilizar materiales restauradores que empleen técnicas de grabado ácido para su colocación ya que estas sustancias desmineralizan sus componentes dando como resultado la exposición de túbulos dentinales abiertos. ${ }^{4,7,8}$

La formación del smear layer es un proceso físico y no una reacción biológica per se. No obstante posee implicaciones clínicas que sí encierran un contexto biológico. No es una estructura estable, debe ser removido con el fin de obtener una unión química y mecánica óptima entre el material de restauración y la estructura dental. El acondicionamiento permitirá que la resina penetre en los túbulos y sus ramificaciones así como la malla colágena de la matriz intertubular y el colágeno de las paredes de los túbulos expuestos por el ácido ${ }^{4}$. No obstante, la presencia del smear layer puede ser benéfica, ya que físicamente, refuerza la reducción del flujo de fluidos proveniente de la dentina $y$, por consiguiente, disminuye su permeabilidad. El aumento en la reducción del flujo de fluidos puede tener un efecto protector para el tejido pulpar ya que 
sería un complemento al mecanismo fisiológico ya existente basado en que de por sí la presión hidrostática de la pulpa puede limitar la difusión a través de los túbulos de la dentina. También lo hace impidiendo la entrada de bacterias en los túbulos dentinales que han sido cortados. ${ }^{4}$

\section{b. Cambios histológicos producto de las preparaciones dentales}

Las primeras reacciones del complejo dentino / pulpar a la preparación dental incluyen un desplazamiento del núcleo del odontoblasto hacia el interior de los túbulos dentinales y una marcada desorganización de los organelos del odontoblasto y de las células adyacentes. La importancia clínica de estos cambios no se ha establecido aun, pero parece tener un efecto sobre la fisiología de la dentina afectada. Parece ser que estos cambios son los responsables de la reacción denominada tracto muerto. ${ }^{4}$

\section{Respuesta de la pulpa a la aplicación de agentes adhesivos}

Las propiedades de los adhesivos per se son fenómenos físicos y químicos, no obstante; debido a que la reacción toma lugar en los tejidos dentales, se considera apropiado discutir estos materiales en un contexto biológico. ${ }^{9,10}$

Se debe prestar una particular atención a las preparaciones que se encuentran en estrecha relación con el tejido pulpar, ya que existen diferencias estructurales muy marcadas entre la dentina superficial y la profunda. Así pues, el número de túbulos dentinales es mayor en dentina profunda (aproximadamente, 75000 túbulos / $\mathrm{cm}^{2}$ ) si se le compara con dentina superficial (20 000 túbulos $/ \mathrm{cm}^{2}$ ). El diámetro interno de los túbulos dentinales cercanos a la pulpa (dentina profunda) es mayor (3.0 um) que aquel encontrado en los túbulos de la dentina superficial $(0,8 \mathrm{um}){ }^{8}$

Los efectos biológicos reportados al utilizar agentes adhesivos poseen un rango que oscila entre ninguno - severos, y esto puede deberse a diversos factores. Las reacciones inflamatorias asociadas a la utilización de algunos agentes adhesivos pueden deberse a: material per se, crecimiento bacteriano en la interfase diente-restauración, combinación de ambos factores. ${ }^{10,11}$ La mayoría de los agentes adhesivos que se han introducido en el mercado, recientemente requieren la remoción parcial o total del smear layer, produciendo de este modo una apertura de los túbulos dentinales lo que puede incrementar exageradamente la permeabilidad de la dentina. El incremento de la permeabilidad dentinal facilita la posibilidad de afectar la pulpa, bien sea por la difusión de productos bacterianos o por los efectos citotóxicos que pueden producir algunos componentes del material restaurador y de los agentes adhesivos; especialmente desde que se sabe que algunos componentes de estos sistemas adhesivos son capaces de penetrar los túbulos dentinales incluso más de 200 - 300 um en dirección pulpar. ${ }^{8,11,12,13}$

Algunas investigaciones basadas en estudios histopatológicos han revelado que los agentes adhesivos pueden provocar una baja incidencia de daño pulpar irreversible, cambios inflamatorios transitorios y formación de dentina irregular (reaccionaria); asimismo, sostienen que estas respuestas inflamatorias pulpares son posiblemente debidas a una irritación por la difusión de algunos de los componentes de los adhesivos una vez se ha realizado el corte de la preparación, especialmente cuando el grosor de dentina remanente es delgado o cuando se expone el tejido pulpar durante la preparación cavitaria. ${ }^{13}$ Además del agente adhesivo per se, numerosas investigaciones reportan la asociación entre la presencia de bacterias en las paredes de las cavidades bajo los materiales restauradores y la inflamación pulpar. Estos autores sugieren que la respuesta pulpar no depende únicamente del tipo de material aplicado sobre el complejo pulpo/dentinal sino de la capacidad que posea el material restaurador de prevenir la microfiltración bacteriana. ${ }^{7,14}$

La vitalidad pulpar depende de la severidad de la respuesta inflamatoria que ha sido inducida por el agente adhesivo, lo que nos sugiere que esta reacción puede ser un evento reversible o irreversible. Esta es una de las mayores preocupaciones al utilizar este tipo de sustancias ya que si el agente adhesivo induce un daño pulpar irreversible el subsiguiente tratamiento endodóntico es inevitable. De acá se desprende que un gran número de factores pueden influenciar la respuesta pulpar al agente adhesivo. Entre ellos, encontramos: composición y citotoxicidad del agente adhesivo, procedimientos operatorios clínicos, grosor de dentina remanente y permeabilidad dentinal. ${ }^{13,14}$

\section{Discusión}

La participación de noxas patógenas físicas, químicas o microbianas como: el calor, la presión, los ácidos, las toxinas, incluye a elementos bacterianos sobre los túbulos dentinarios, donde se produce un mecanismo hidrostático, la aspiración o vacuolización de los odontoblastos. ${ }^{15}$ Puede ser que este término histológico debería ser cambiado por otro término más clínico que traduzca el dolor provocado post-maniobras operatorias (o de otras causas) como es la hipersensibilidad dentaria secundaria. Llamas y cols. definieron que el término sensibilidad dentinaria es la consecuencia de la permeabilidad al faltar el sellado de los túbulos en las paredes y suelo de las preparaciones cavitarias $^{16}$. Sin embargo, Torabinejad y cols. mostraron que los estímulos químicos, mecánicos o bacterianos que irritan la pulpa dental generan alteraciones inflamatorias en el mismo; mientras que las injurias moderadas de corta duración, causan daño reversible y el tejido se recupera; en contraste con las injurias severas o persistentes en el tejido pulpar, que originan pulpitis irreversible y su posterior necrosis. ${ }^{17}$ Pero Escobar observó que varios autores destacaron las diferencias morfológicas entre la dentición primaria y permanente, esto hace que los procesos pulpares y periapicales difieran entre las dos denticiones; por lo que, la pulpa de los dientes primarios responden más rápidamente a la caries dental que la pulpa de los dientes permanentes; muestran además que los cambios inflamatorios pueden desarrollarse cuando las bacterias han penetrado tan solo $1.8 \mathrm{~mm}$ dentro de la pulpa. ${ }^{18}$ López- Marcos, en su revisión de literatura, refirió que los mecanismos directos para llegar a la pulpa, son los microorganismos a través de los túbulos dentinarios expuestos, ya sea por caries, traumatismos o factores irritantes (productos bacterianos, bacterias, endotoxinas, etc., que al penetrar a través de los túbulos dentinarios, destruyen el odontoblasto y las células subyacentes. ${ }^{19}$ Asimismo, Queralt, en la presentación de su manual, mostró que la caries expone a la dentina y produce reacciones pulpares profundas que tienden a reducir la permeabilidad dentinal y a estimular la formación de dentina adicional. Estas reacciones son llevadas a cabo con cambios en los fibroblastos, nervios, vasos sanguíneos, odontoblastos, leucocitos, y el sistema inmune. Además, la relación funcional entre la pulpa y la dentina se puede observar en varios aspectos: la pulpa es capaz de crear dentina fisiológicamente y en respuesta a un estímulo externo, la pulpa contiene nervios que aportan la sensibilidad dentinaria, el tejido co- 
nectivo pulpar es capaz de responder a lesiones dentinarias sin ser estimulado directamente, la encapsulación de la pulpa dentro de la dentina crea un ambiente que influencia negativamente su potencial de defensa. ${ }^{2}$ Más tarde, Betauncourt realizó una investigación de tipo observacional descriptiva, que tuvo como objetivo conocer la incidencia de las lesiones pulpares y periapicales y su relación con algunas variables clínicas en 1137 alumnos entre 4 y 12 ańos de edad procedentes del área del Policlínico Docente de Playa, registrando que $5,2 \%$ de los examinados estaban afectados por dichas lesiones. Las lesiones periapicales predominaron sobre las pulpares. Las principales causas fueron: la caries dental en $64,6 \%$, con obturaciones deficientes $18,6 \%$, y los traumas con 16,8 \%. Las obturaciones deficientes que se presentaron estuvieron determinadas por la invasión bacteriana a los tejidos de la pulpa a través de las microfiltraciones; a su vez, coincide con otros autores que refieren que la manifestación biológica más importante de la microfiltración provocada por la obturación deficiente es el reinicio de caries y la patología pulpar. ${ }^{20}$

\section{Conclusiones}

- Las agresiones como los procesos cariosos o las restauraciones dentales, originan alguna respuesta pulpar. Estas reacciones son diferentes a las que se observan en otras áreas del organismo y ponen en peligro el tejido pulpar. Según múltiples investigaciones, el principal irritante pulpar, es de origen bacteriano lo que produce caries dental, mientras que su reacción inflamatoria dependerá de la duración e intensidad de la injuria y del tipo de dentición.

- Existe relación directa entre el tipo de preparación y profundidad realizada en dentina, técnica empleada y material utilizado, no solo basta con devolver la forma, función, estética correcta y adecuada al diente, se debe tratar de proteger la vitalidad del diente para evitar alteraciones que den lugar a síntomas molestos para el paciente, aunque sea de forma reversible. Asimismo, la respuesta pulpar no depende únicamente del tipo de material aplicado sobre el complejo pulpo-dentinal, sino de la capacidad que posea el material restaurador de prevenir la microfiltración bacteriana.

\section{Referencias bibliográficas}

1. Mount GJ, Hume WR. Conservación y restauración de la estructura dental. Harcourt Brace Ediciones. 1ra. edición. 1999. 37- 43.

2. Queralt R, Durán-Sindreu F, Ribot J, Roig M. Manual de Endodoncia. Parte 4. Patología pulpo-periapical. Rev Oper Dent Endod 2006; 5:24.

3. Cohen S. Vías de la pulpa. 9na. Edición. 2008. pp. 523 - 550.

4. Mjor IA. Pulp-dentin biology in restorative dentistry. Part 2: initial reactions to preparation of teeth for restorative procedures. Quintessence Int. 2001 Jul-Aug; 32(7): 53751.

5. Perdigao J. Dentin bonding as a function of dentin structure. The Dental Clinics of North America. 2002; 46: 277-301.

6. Carpena G, Baratieri LN. Dental adhesion: present state of the art and future perspectives. Quintessence Int 2002; 33: 213-224.

7. Hebling J, Giro EM, Costa CA. Human pulp response after an adhesive system application in deep cavities. J Dent. 1999 Nov; 27(8): 557-64.

8. Costa CA, Giro EM, Do Nascimento AB, Teixeira HM, Hebling J. Short-term evaluation of the pulpodentin complex response to a resinmodified glass-ionomer cement and a bonding agent applied in deep cavities. Dent Mater 2003; 19(8): 739-46.

9. Mjor IA. Pulp-dentin biology in restorative dentistry. Part 6: Reactions to restorative materials, toothrestoration interfaces and adhesive techniques. Quintessence Int. 2002; 33(2): 35-63.

10. Al-Dawood A, Wennberg A. Biocompatibility of dentin bonding agents. Endod Dent Traumatol. 1993; 9(1): 1-7.
11. Sonoda H, Sasafuchi Y, Kitasako Y, Arakawa M y col. Pulpal response to a fluoride-releasing all-in-one resin bonding system. Oper Dent. 2002; 27(3): 271-7.

12. Ivanyi I, Balogh AE, Rosivall L, Nyarasdy I. In vivo examination of the scotchbond multi - purpose dental adhesive system in rat (vitalmicroscopic study). Operative Dentistry, 2005; 25: 418-423.

13. Chen RS, Liu CC, Tseng WY, Jeng $\mathrm{JH}$, Lin CP. Cytotoxicity of three dentin bonding agents on human dental pulp cells. J Dent. 2003 Mar; 31(3): 223-9.

14. Odontología General, Endodoncia. Características clínicas de la permeabilidad dentinaria: sensibilidad dentinaria. Disponible en: http:// dentalw.com/papers/endo/art8. htm.

15. Llamas R, Jiménez A y col.: Desensibilización dentinaria con fluoruro sódico al $2 \%$ durante la preparación cavitaria. Rev Rurop Odontoestomatol, 1990; 2: 425-428.

16. Torabinejad, M. Mediators of acute and chronic perirradicular lesions. Oral Surgery Oral Medicine and Oral Pathology, 1994; 78(4): 511521

17. Escobar F. Odontología Pediátrica. Ed. Universitaria Concepción; 1991.

18. López-Marcos JF. Etiología, clasificación y patogenia de la patología pulpar y periapical. Med Oral Patol Oral Cir Bucal 2004; 9 Suppl: S5262.

19. Betancourt NM. Lesiones pulpares en escolares del área de atención del policlínico docente de playa. Rev Haban Cienc Méd [online]. 2009; $8(2)$.

20. Hutchins M. Pulpal Microvascular response to acute dentinal exposure. The University of Texas Healt Science Center at Houston. Disponible en: http://www.uth.tmc.edu/courses /dental/pulpalmicro/pulp.htm

Fecha de recepción: 19-5-10

Fecha de aprobación: 10-06-10 